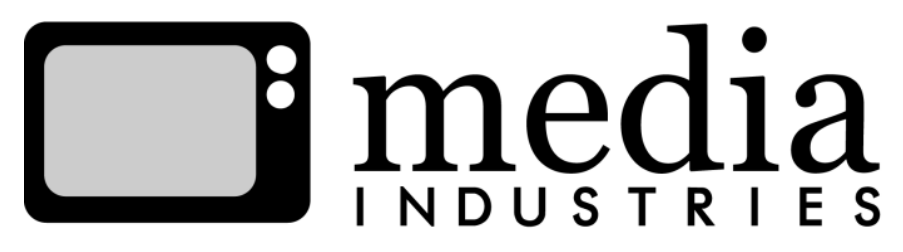

\title{
Transnational TV: \\ What Do We Mean by "Coproduction" Anymore?
}

\author{
Michele Hilmes ${ }^{1}$ \\ University of Wisconsin-Madison \\ mhilmes [AT] wisc.edu
}

\begin{abstract}
:
Over the last two decades, transnational coproduction has become the new normal for high-end television drama and documentary. Obscured behind the attention paid to that other new global phenomenon, the reality format, other innovative program forms have emerged alongside newly constituted transnational publics, rich new constellations of cultural engagement, and a host of evolving practices of cooperative production. This article attempts to identify some of the issues that arise in studying new forms of transnational television coproduction between the United States and the United Kingdom, the world's two largest global program suppliers, and to think through the research questions needed to explore them.
\end{abstract}

Keywords: Television, Globalization, United Kingdom, United States, Nationalism

In one sense, coproduction is the natural state of film and television. Every film or television program ever made results from the efforts of more than one person or entity, and when the credits roll, the numerous creative, financial, management, and service companies that contributed to a show's success are acknowledged (or not) in a strict hierarchy. Diffusely shared authorship is the norm. Yet traditionally when the partners come from different national locations rather than occupying the same national space, a whole new set of considerations and terms arise: it becomes an "international coproduction." This is a term used by the film industry since the 1940s, indicating a partnership between two or more different national production entities aimed at taking advantage of locality-specific tax incentives, funding opportunities, locations, and talent. Such international or "treaty" coproduction involves meeting a set of highly specific qualifications and requirements set by national or regional film boards, often rewarded by hefty subsidies. Major production companies long ago developed the practice of setting up subsidiaries in nations around the world to take advantage of international 
coproduction on an ongoing basis, and many countries have encouraged coproduction as a way to manage and derive greater benefit from "runaway" commercial filmmaking.

In television, the situation has been somewhat more complicated. Given the strong national basis of broadcasting, with most nations supporting their own powerful and well-financed central public broadcasters with mandates for domestic production, international coproduction - particularly with commercial partners - historically met with various forms of resistance and was slower to develop. National broadcasters typically found it preferable simply to import popular foreign television shows, at a relatively low cost, in order to put scarce public funding into preferred types of original, nationally specific programs. However, Britain and the United States began actively coproducing drama and documentary programs in the 1970s, at first primarily for the public-service market but, as cable television opened up new venues in the 1980s, for the commercial market as well. With the expansion of the independent broadcasting sector in Europe in the 1990s, followed by the advent of digital platforms in recent decades, coproduction has exploded to become the "new normal" in high-end drama and documentary, in particular. The United States and the United Kingdom became not only the two largest global exporters of television programs but also each other's biggest customers and most frequent coproduction partners. This relationship has given rise to innovative program forms, newly constituted transnational publics, rich new constellations of cultural engagement, and a host of evolving practices of cooperative production that have been obscured by the attention paid to that other new global phenomenon, the reality format. Here I want to identify issues that arise in studying new forms of transnational television and attempt to pose a few research questions needed to explore them.

From a US vantage point, the world of television suddenly opened up to drama from around the world, focusing not on "reversioned" content to supposedly suit American audiences (and so often failing) but on programs in their original forms, complete with subtitles. The off-piste success of series like Borgen (2010-13), The Fall (2013), and Engrenages/Spiral (2005-)-never carried by US-based cable or broadcast channels but experienced via DVD, Netflix, and other digital means - has awakened a spate of articles directed at US audiences with titles like "Five Great International Shows That Should Be Streaming," 2 "The International Language of Tube," 3 and "The Elusive Pleasures of French TV Series." 4 Those titles all share a tone of mild astonishment that such programs exist-where have they been all our lives? This despite the fact that PBS's Masterpiece series (1971-) has been coproducing and importing British drama for more than three decades; BBC America brings a steady current of British-produced programs into US cablespace; and of course, a world of Spanish-language television is right there for easy consumption, much of it produced in Mexico and South and Central America (though for the most part only subtitled via closed-captioning and not often noticed or reviewed by Englishlanguage outlets). ${ }^{5}$ How do certain international programs achieve critical and popular recognition while others are ignored? What role does nontraditional distribution over digital platforms play in opening up the longstanding ethnocentric enclosures of American television? Scholarly attention has mainly focused on the pervasive spread of US-originated forms and narratives, with the influence of other cultures on US television largely neglected. ${ }^{6}$ Far more research is needed on the construction of new transnational viewing publics as well as on the largely online spaces where their viewing takes place and where their critical opinions are registered.

From the perspective of other countries, where US-produced programs have long been featured on domestic channels and via satellite, digital globalization has meant wider access to more of 
the same rather than something completely different. What may prove a more lasting change, however, is the way that domestic drama production around the world is being conceptualized, funded, scripted, and cast with a diverse global market-and, often, global partnershipsforemost in mind. Though Borgen, The Fall, and Engrenages were not coproductions as such, all were produced by a national broadcaster (DR, BBC Two, and Canal+, respectively) with transnational distribution a clear goal; two have since picked up international partners, and all three have attracted considerable transnational audiences and critical attention. Such success has caused industry analysts to note the return of international coproduction to the world of television drama after its decades-long eclipse by reality formats. ${ }^{7}$ The staid international, or "treaty," coproductions prominent in television's earlier decades have been transformed into a practice that more and more frequently partners public-sector broadcasters with independents and large commercial companies from two or more nations. The United States still remains the most sought-after partner due to its sizable audience. I call this phenomenon "transnational coproduction" to distinguish it from previous practices, and to indicate the new set of issues it raises.

Transnational coproduction in the current era includes not just cofinancing or presale of distribution rights (i.e., putting money into a series upfront, but contributing very little creatively to the production): it also involves a creative partnership in which national interests must be combined and reconciled, differing audience tastes considered, and, often, the collision of public-service goals with commercial expectations negotiated. Historically, the issue of creative control has been a touchy one since nationally-funded producers like the BBC insist that their coproduction partnerships involve no compromise with public-service goals nor with the best interests of British audiences, sometimes in the face of casting, setting, and plot decisions that clearly bow to their (often American) coproducers. Meanwhile, commercial partners assure their investors that, in fact, the program made with their public service coproducer has broader audiences firmly in mind and will not be held captive to a narrowly national address. Such tensions produce a public discourse that can directly contradict the actual conditions and processes of coproduction. How does creativity work in various forms of coproduced narrative? How do transnational partners negotiate the conflicting demands of national specificity and global appeal? Where can international influences open up a drama productively to broader audiences, creating a text that encourages cross-cultural understanding - and where does it work to destroy or marginalize authentic experience? These questions demand research that looks not just at political-economic conditions but that examines texts, production practices, critical discourses, and audience uses as well. ${ }^{8}$

In the meantime, interesting collisions occur. Top of the Lake (2013), the television miniseries written by New Zealand filmmaker Jane Campion, was originally intended as an Australian/UK/US coproduction but lost the participation of the Australian Broadcasting Corporation when American actress Elisabeth Moss was cast in the leading role instead of an Australian or New Zealand lead: an example of global appeal in direct conflict with national or regional specificity. Acclaimed Swedish-Danish coproduction Bron/Broen (2011-), a crime drama about a body found on the bridge between the two countries, aired in its original version, subtitled, on the broadcast schedules of many countries, including on BBC Four, and could be widely obtained on DVD. (The online streaming platform Hulu will distribute it in 2014). But two national reversionings have already appeared: the FX channel's The Bridge (2013-) sets its action on the border between the United States and Mexico, and a British-French coproduction, 
The Tunnel (2011-), takes the action underwater to the Channel Tunnel on Sky Atlantic and Canal+. In each version, police from two countries must cooperate.

The most acclaimed British-American co-production in recent years, Downton Abbey (2010-) also highlights the narrative appeal of a program that foregrounds international relationships and provides the opportunity for reflection on cultural similarities and differences. Though set in an aristocratic England of the past, its plot is based on the clash of sensibilities between American and British characters, between upstairs and downstairs, between traditional class hierarchies and a growing resistance to them. As Alessandra Stanley argues, Downton Abbey "cleverly filters British social history through the biases and preoccupations of American pop culture . . . what really entrances viewers here isn't Anglophilia or a vestigial yearning for a monarch, but rather the mirror that 'Downton Abbey' holds up to America." 9 It is a mirror that reflects the sensibilities of viewers around the world as well, as its global distribution attests, though its lack of complete realism and many historical improbabilities have attracted considerable criticism. Yet here, perhaps, is one form that the transnational television coproduction might constructively take: interrogating the claims of nation and inflecting them with the intersectionality of identity that is the hallmark of contemporary existence-or, at least, of television viewing. We need to begin to examine the transnational dimensions of the national television "box" precisely by exploring the boundary collisions inherent in transnational coproduction.

${ }^{1}$ Michele Hilmes is Professor of Media and Cultural Studies in the Department of Communication Arts at the University of Wisconsin-Madison. Her work focuses on media history and historiography, particularly in the areas of transnational media and sound studies. She is the author or editor of several books in this field, including Radio Voices: American Broadcasting 1922-1952 (1997), Network Nations: A Transnational History of British and American Broadcasting (2011), Only Connect: A Cultural History of Broadcasting in the United States (4th ed., 2013), and Radio's New Wave: Global Sound in the Digital Era (2013), coedited with Jason Loviglio.

2 Margaret Lyons, “5 Great International Shows that Should Be Streaming," Vulture, July 10, 2013.

${ }^{3}$ June Thomas, “The International Language of Tube," Slate, November 26, 2013.

4 Alessandra Stanley, "The Elusive Pleasures of French TV Series," New York Times, August 29, 2013.

${ }^{5}$ Univision began subtitling its prime-time programs in English in 2012.

${ }^{6}$ With some significant and encouraging exceptions; see Jeffrey S. Miller, Something Completely Different: British Television and American Culture (Minneapolis: University of Minnesota Press, 2000); Simone Knox, "Masterpiece Theatre and British Drama Imports on US Television: Discourses of Tension," Critical Studies in Television 7, no. 1 (2012): 29-48; Elke Weissmann, Transnational Television Drama: Special Relations and Mutual Influence Between the US and the UK (New York: Palgrave Macmillan, 2012).

7 Tim Westcott, “TV Drama Riding High in International Market," Screen Digest, April 11, 2013; John Plunkett, "Why British TV Producers Are Going Global," Guardian, March 29, 2013.

${ }^{8}$ Some excellent new work has made a start at examining these issues: Sheron Neves, "Running a Brothel from Inside a Monastery: Drama Co-Productions at the BBC and the Trade Relationship with America from the 1970s to the 1990s" (PhD diss., 
University of London-Birkbeck, 2013) and Jonathan Bignell and Simone Knox, Transatlantic Television: British and American TV Drama (London: I. B. Tauris, forthcoming).

9 Alessandra Stanley, "A Trans-Atlantic Romance Continues," New York Times, January $2,2014$. 


\section{Bibliography}

Bignell, Jonathan, and Simone Knox. Transatlantic Television: British and American TV Drama. London: I. B. Tauris, forthcoming.

Knox, Simone. "Masterpiece Theatre and British Drama Imports on US Television: Discourses of Tension." Critical Studies in Television 7, no. 1 (2012): 29-48.

Lyons, Margaret. "5 Great International Shows that Should Be Streaming." Vulture. Last modified July 10, 2013.

Miller, Jeffrey S. Something Completely Different: British Television and American Culture. Minneapolis: University of Minnesota Press, 2000.

Neves, Sheron. "Running a Brothel from Inside a Monastery: Drama Co-Productions at the BBC and the Trade Relationship with America from the 1970s to the 1990s." PhD diss., University of London-Birkbeck, 2013.

Plunkett, John. “Why British TV Produces Are Going Global." Guardian, March 29, 2013.

Stanley, Alessandra. “A Trans-Atlantic Romance Continues.” New York Times, January 2, 2014.

- - -. “The Elusive Pleasures of French TV Series.” New York Times, August 29, 2013.

Thomas, June. “The International Language of Tube.” Slate. Last modified November 26, 2013.

Weissmann, Elke. Transnational Television Drama: Special Relations and Mutual Influence Between the US and the UK. New York: Palgrave MacMillan, 2012.

Westcott, Tim. “TV Drama Riding High in International Market." Screen Digest. Last modified April 11, 2013.

\section{$(\mathrm{Cc})) \mathrm{BY}-\mathrm{NC}-\mathrm{ND}$}

Copyright (C) 2014 (Michele Hilmes). Media Industries is an open-access, peer-reviewed, online academic journal. As such, we aim to participate in the open exchange of information. This work is licensed under a Creative Commons Attribution Noncommercial No Derivatives (by-nc-nd) License. Under this license, this work is available for sharing and noncommercial distribution provided the appropriate attribution is given. 